\section{NEGOTIATING DISCOURSES THROUGH PHOTOVOICE: YOUNG ETHIOPIANS' VISUAL CONSTRUCTIONS OF SAFETY}

${ }^{1}$ Nick Malherbe, ${ }^{2}$ Shahnaaz Suffla, ${ }^{3}$ Mohamed Seedat, ${ }^{4}$ Umesh Bawa. ${ }^{1}$ University of South Africa, South Africa; ${ }^{2}$ South African Medical Research Council, South Africa; ${ }^{3}$ University of South Africa, South Africa; ${ }^{4}$ University of the Western Cape, South Africa

\subsection{6/injuryprev-2016-042156.131}

Background Research concerning child safety within Africa is dominated by adult-centric linguistic-based research. Such research has radically individualised child safety and denies children any kind of agency in conceptualising their protection. Despite the immense communicative potential inherent within visual methodologies, very few community-based research studies have meaningfully considered visual constructions of child safety. Methods When working with youth from contexts with which researchers are unfamiliar, visual methodologies and analyses are able to transcend much of the developmental and cultural barriers to communication that are inherent to linguistically-focussed research methods. By employing a visual discourse analysis on six photographs captured by Ethiopian youth in a Multi-Country Photovoice Project on child safety, this study aims to showcase the manner in which analysing visual discourses is able to give voice to children within child safety research.

Results It was found that participants drew predominantly on two discourses; Humanising Capital and Unity, both of which resisted a number of hegemonic discourses surrounding child safety. Participants were able to reappropriate and challenge dominant, adult-centric depictions of child safety by constructing unity among children as well as national and economic secuity as that which comprises children's safety.

Conclusions Participants' visual constructions served as a meaningful mode of communication, as well as a relevant approach of implementing youth ownership of meaning-making processes within community-based child safety research. The visual meaning-making processes catered to the participants' developmental, cultural and linguistic positionality, and allowed them to challenge the dominant child safety discourses in which their voices have traditionally been ignored.

\section{TEACHING PRINCIPLES AND PRACTICE OF INJURY PREVENTION WITH EVOLVING CURRICULUM DESIGN 1988-2015}

${ }^{1,2}$ Carolyn Cumpsty-Fowler, ${ }^{2}$ Maryanne Bailey, ${ }^{2}$ Keshia Pollack, ${ }^{2}$ Andrea Gielen. ${ }^{1} J o h n s$ Hopkins University School of Nursing; ${ }^{2}$ Johns Hopkins Bloomberg School of Public Health, USA

\subsection{6/injuryprev-2016-042156.132}

Background In 1988, the Johns Hopkins Centre for Injury Research and Policy held its first Summer Institute: Principles and Practice of Injury Prevention (SI). The 22nd SI cohort completed training in 2015. At least 750 people from diverse professional backgrounds and countries have completed this intensive, introductory training. While acknowledging the evaluative limitations imposed by missing data for early cohorts, we describe key lessons learned and applied for curriculum enhancement.

Objectives Describe SI's evolving focus and instructional design using a six-step curriculum process model: problem identification and general needs assessment; targeted training needs assessment; development of training goals and objectives; educational strategies; implementation; feedback and evaluation.
Stimulate generative conversation with participants about injury prevention training priorities and strategies.

Results Throughout its long history, SI's commitment to providing excellent, current, relevant training has required extensive changes to design and delivery. The current curriculum is based on the nine Core Competencies for Injury and Violence Prevention, and focused on developing transferable skills. Participants report the systematic problem solving framework and facilitated, scenario-based practical application sessions throughout SI, develop their competence. Skills cited as most important are critical and systematic thinking; enhanced capacity to use conceptual frameworks and evaluative thinking throughout the IP process to challenge assumptions; and learning the importance of asking and answering the question, what are we doing and why?

Conclusions Evolving curriculum design must be rigorous and systematic; informed by adult learning theory, stakeholders, emerging issues in the injury field, and evaluated continuously.

\section{CANADIAN CHILD SAFETY REPORT CARD: A COMPARISON OF INJURY PREVENTION PRACTICES ACROSS PROVINCES}

${ }^{1}$ Liraz Fridman, 'Jessica Fraser-Thomas, ${ }^{2}$ lan Pike, ${ }^{1}$ Alison Macpherson. 'Department of Kinesiology and Health Sciences, York University; ${ }^{2}$ Department of Paediatrics, University of British Columbia and BC Injury Research and Prevention Unit, Child and Family Research Institute, Canada

\subsection{6/injuryprev-2016-042156.133}

Background Health-based report cards have been used as a tool to disseminate research findings to parents, government agencies, stakeholders, and the general public. In Canada, health-based report cards such as the How Canada Performs report provides a comparison of how provinces measure up to one another on a number of health-based indicators. However, few child health report cards discuss implications for primary prevention policy or practice.

Methods This project plans to develop and communicate child safety report cards for each of the 10 Canadian provinces in 3 phases. Phase I is an interprovincial comparison of injury hospitalizations in each Canadian province over time. Phase II is an examination of evidence-based provincial policies. Phase III combines results from I and II and creates Canadian Child Safety Report Cards for each province.

Results In Canada, Saskatchewan was the province with the highest rate of injury hospitalisation per 100,000 between 2006 and 2012, but incidence decreased from 967 to 852 over the 6 year period, despite not having policies that meet best practice. Ontario had the lowest rate of injury hospitalisation per 100,000, however the incidence rate increased slightly from 451 to 479. Only British Columbia decreased the incidence of injuries compared to the Canadian average. The rate decreased from 667 to 515 between 2006 and 2012. This change in incidence over time is observed in a province that complied with best practice evidence-based injury prevention policies.

Conclusions This is the first study to compare injuries among children and youth across Canadian provinces in terms of hospitalisation, and the enactment of evidence-based policies. This data may allow the influence of all spectrums of prevention by resulting in the harmonisation of policy and legislation in Canada. Similar projects in the European Union have started to yield results in terms of harmonising prevention policies across member states. 